\title{
Improvement of L-Arabinose Fermentation by Modifying the Metabolic Pathway and Transport in Saccharomyces cerevisiae
}

\author{
Chengqiang Wang, Yu Shen, Yanyan Zhang, Fan Suo, Jin Hou, and Xiaoming Bao \\ The State Key Laboratory of Microbial Technology, Shandong University, Shan Da Nan Road No. 27, Jinan 250100, China \\ Correspondence should be addressed to Xiaoming Bao; bxm@sdu.edu.cn
}

Received 18 June 2013; Accepted 25 August 2013

Academic Editor: Gotthard Kunze

Copyright (C) 2013 Chengqiang Wang et al. This is an open access article distributed under the Creative Commons Attribution License, which permits unrestricted use, distribution, and reproduction in any medium, provided the original work is properly cited.

The L-arabinose utilization pathway was established in Saccharomyces cerevisiae, by expressing the codon-optimized $\operatorname{araA}$, araB, and araD genes of Lactobacillus plantarum. After overexpressing the TAL1, TKL1, RPE1, RKI1, and GAL2 genes and adaptive evolution, the L-arabinose utilization of the recombinant strain became efficient. The resulting strain displayed a maximum specific growth rate of $0.075 \mathrm{~h}^{-1}$, a maximum specific L-arabinose consumption rate of $0.61 \mathrm{~g} \mathrm{~h}^{-1} \mathrm{~g}^{-1}$ dry cell weight, and a promising ethanol yield of $0.43 \mathrm{~g} \mathrm{~g}^{-1}$ from L-arabinose fermentation.

\section{Introduction}

To reduce the dependence on fossil fuels, the worldwide production of bioethanol was increased from $\sim 45$ million liters in 2005 to 113 billion liters in 2012 [1-3]. The future large-scale production of fuel ethanol will most likely be based on abundant lignocellulosic materials instead of sugar and grain, which are food for humans and animals [4]. Cost-effective fuel ethanol production from lignocellulosic materials requires the full use of the raw materials. One goal of bioethanol production is to endow the fermentation microorganism with the capacity to convert all of the sugars in lignocellulosic materials $[5,6]$. Approximately $3-15 \% \mathrm{~L}-$ arabinose component can be recovered from lignocellulosic materials [7]. It is therefore necessary to construct an Larabinose fermenting microorganism to increase the utilization of this sugar [8].

Two types of L-arabinose metabolic pathways exist in fungi and bacteria. The aldose reductase (AR), L-arabitol4-dehydrogenase (LAD), L-xylulose reductase (LXR), and $\mathrm{D}$-xylitol dehydrogenase $(\mathrm{XDH})$ constitute the fungal Larabinose metabolic pathway. The reaction catalyzed by AR and LXR is coupled with the oxidation of NADPH to $\mathrm{NADP}^{+}$, and the LAD and XDH use $\mathrm{NAD}^{+}$as a cofactor [9]. The xylulose produced is phosphorylated and enters the pentose-phosphate pathway (PPP). The bacterial L-arabinose metabolic pathway is cofactor independent and consists of L-arabinose isomerase (AraA), L-ribulokinase (AraB), and L-ribulose-5-phosphate 4-epimerase (AraD). The Dxylulose-5-phosphate produced enters the PPP $[9,10]$. Both $\mathrm{L}$-arabinose metabolic pathways were established in Saccharomyces cerevisiae, which is the traditional ethanol-producing microorganism with excellent sugar fermenting capacity and tolerance to the harsh environment, but it cannot ferment Larabinose [11]. Not surprisingly, a redox imbalance occurs in the recombinant $S$. cerevisiae strain containing the fungal Larabinose metabolic pathway. The yield of the by-product Larabitol was as high as $0.48 \mathrm{~g} \mathrm{~g}^{-1}$ of pentose sugar consumed in the $\mathrm{D}$-xylose and L-arabinose cofermentation, although the strain expressing $\mathrm{NADH}$ preferred $\mathrm{AR}$ and LXR to decrease the redox imbalance [12].

Compared to the fungal L-arabinose metabolic pathway, the bacterial pathway is simpler and cofactor independent. However, because of the lack of effective activity assays for enzymes involved in the bacterial L-arabinose metabolic pathway, the optimization of this pathway in $S$. cerevisiae was not straightforward. The $S$. cerevisiae strain expressing the $\operatorname{ara} A, \operatorname{araB}$, and $\operatorname{araD}$ genes of Escherichia coli could not utilize L-arabinose. However, after the E. coli L-arabinose isomerase gene was replaced with the araA cloned from 
Bacillus subtilis, the strain could grow and produce ethanol on L-arabinose after several circles of adaptive growth [13, 14]. Furthermore, the L-arabinose utilization was further improved by changing the codon usage of the bacterial araA, $a r a B$, and $a r a D$ genes to the preferred yeast codons [15]. The L-arabinose metabolic genes of Lactobacillus plantarum matched the codon usage of $S$. cerevisiae more closely than the genes previously reported. Wisselink et al. [8] introduced multiple copies of $\operatorname{araA}$ and $a r a D$ and a single copy of araB of $L$. plantarum into S. cerevisiae. After overexpressing the genes encoding the enzymes of nonoxidative PPP and extensive adaptive evolution, the resulting strain exhibited a high ethanol yield up to $0.43 \mathrm{~g} \mathrm{~g}^{-1}$ during anaerobic growth on L-arabinose, with a high arabinose consumption rate $\left(0.70 \mathrm{~g} \mathrm{~h}^{-1} \mathrm{~g}^{-1}\right.$ dry cell weight (DCW) $)[8]$. The metabolome, transcriptome, and metabolic flux analysis of a more evolved strain revealed that higher expression levels of the galactose transporter, transketolase, and transaldolase isoenzymes benefit the growth of S. cerevisiae on L-arabinose [16].

In the present work, the unique codon-optimized $\operatorname{araA}$, $a r a B$, and $a r a D$ genes of $L$. plantarum were expressed in the $S$. cerevisiae strain CEN.PK102-3A at different levels. Next, the genes TAL1, TKL1, RPE1, and RKI1 involved in PPP were overexpressed in this recombinant strain. The resulting strain was sequentially selected on L-arabinose under aerobic conditions and in oxygen-limited conditions. A strain with a significantly enhanced L-arabinose utilization capacity was obtained. The L-arabinose metabolic capacity of the evolved strains and the strain that also overexpressed the transporter gene GAL2 were investigated. The factors affecting L-arabinose metabolism efficiency are discussed.

\section{Materials and Methods}

2.1. Media and Culture Conditions. The yeast synthetic complete medium (SC) containing $1.7 \mathrm{~g} \mathrm{~L}^{-1}$ yeast nitrogen base (YNB, Sangon, China) and $5 \mathrm{~g} \mathrm{~L}^{-1}$ ammonium sulfate (Sangon, China), with additional carbon sources of glucose (Sangon, China) or L-arabinose (Sinopharm, China), was used for yeast cultivation. The complete supplement mixture, $0.77 \mathrm{~g} \mathrm{~L}^{-1}$ CSM-URA or $0.67 \mathrm{~g} \mathrm{~L}^{-1}$ CSM-LEU-URA (MP Biomedicals, Solon, $\mathrm{OH}$ ), was added to maintain the required plasmids with auxotrophic selection when necessary. For strains with the KanMX4 marker, the medium was supplied with $200 \mu \mathrm{g} \mathrm{mL}^{-1}$ of the antibiotic G418 sulfate (Promega, Madison, WI, USA). All yeasts were cultivated at $30^{\circ} \mathrm{C}$.

2.2. Codon Adaptation Index Analysis. The codon adaptation index (CAI) is used to illustrate the preference of codon usage in specific species [24]. For the CAI analysis, CODONW (http://mobyle.pasteur.fr/cgi-bin/MobylePortal/ portal.py?form=codonw) [15] was used.

2.3. Plasmid and Strain Construction. E. coli DH5 $\alpha$ [12] was used for subcloning. S. cerevisiae strains and plasmids used in this study are listed in Table 1 . The primers used in this study are listed in Table 2.
The unique codon-optimized $\operatorname{ara} A, \operatorname{araB}$, and $\operatorname{araD}$ genes encoding the L-arabinose isomerase (GenBank: CCC80517.1), L-ribulokinase (GenBank: CCC80519.1), and L-ribulose-5phosphate 4-epimerase (GenBank: CCC80518.1) of L. Plantarum were artificially synthesized and ligated between the HXT7 promoter and PGK1 terminator sequences of plasmid $\mathrm{pHX}$, which was constructed by substituting the PGK1p of plasmid YEp24-PGKp [20] with HXT7p, containing sites for the restriction enzymes Kpn I and Sma I. The HXT7p-araDPGK1t fragment was amplified by PCR with terminal sites for the restriction enzymes Hind III and Bln I and then inserted into the Hind III and Nhe I sites of YIp5, resulting in plasmid YIp5-araD. The HXT7p-araA-PGK1t fragment containing terminal $\mathrm{Bgl}$ II and Sal I sites was inserted into the $B a m \mathrm{H}$ I and Sal I sites of YIp5-araD, resulting in the plasmid YIp5-araAD. The HXT7p-araB-PGK1t fragment with Eag I and Stu I sites was inserted into the Eag I and Stu I sites of YIp5-araAD, resulting in the plasmid YIp5-ara (Figure 1(a)). The TEF1 promoter fragment (with terminal sites for Hind III and Sal I) and the PGK1 terminator fragment (with terminal sites for Bam H I and Hind III) were cloned from the plasmids pJFE3 [23] and pYMIKP [25], respectively. These two fragments were ligated and inserted into the plasmid pYX242 to construct a vector, pYX242-WS, with two sites that can be used to express genes. Then, the gene araA was inserted between the Sal I and Sac I sites of this vector under control of the TEF1 promoter and the PloyA terminator for its expression, and the resulting plasmid was named pYX2422TEF1araA (Figure 1(b)). The plasmid pYX2422-HXT7araA (Figure 1(b)) was constructed using the fragment of $H X T 7 p$ to displace the TEF1p fragment of plasmid pYX2422-TEF1araA; the joints were $B a m \mathrm{H}$ I and Sal I recognition sequences. The gene GAL2 was cloned from the chromosomal DNA of CEN.PK102-3A and then inserted into the Xba I and Sal I sites of plasmid pJFE3, resulting in plasmid pJFE3-GAL2. The URA3 fragment of plasmid pJFE3-GAL2 between the Nde I and $A p a$ I sites was replaced by the KanMX4 gene cloned from pUG6 [18], resulting in plasmid pJFE318-GAL2 (Figure 1(c)).

The yeast transformation was performed using the lithium acetate transformation method [26]. The plasmid YIp5ara was linearized at the Stu I site and then transformed into CEN.PK102-3A. The transformants with the $\operatorname{araA}$, araB, and $a r a D$ genes integrated into the chromosomal $U R A 3$ gene were selected in SC medium containing CSM-URA, and after being confirmed by sequencing, the desired transformant was named BSW1A1. Plasmids pYX242, pYX2422-HXT7araA, and pYX2422-TEF1araA were transformed into BSW1A1, resulting in BSW1AY, BSW1A7, and BSW1AT, respectively. The linearized PJPPP3, which contains the expression frames of genes TAL1, TKL1, RPE1, and RKI1 [19], was integrated into the chromosome of BSW1AT at the GRE3 gene locus, resulting in strain BSW2AP. The strain BSW2AP was adapted on $20 \mathrm{~g} \mathrm{~L}^{-1} \mathrm{~L}$-arabinose under aerobic conditions and then under oxygen-limited conditions. Once the stationary phase was reached, a new batch was initiated by transferring the culture into fresh medium with an initial biomass of $0.15 \mathrm{~g} \mathrm{DCW} \mathrm{L}^{-1}$. When the doubling time of the strain stabilized, mutant BSW3AP was selected from the adapted 
TABLE 1: S. cerevisiae strains and plasmids used in this study.

\begin{tabular}{|c|c|c|}
\hline & Relevant genotype & Source/reference \\
\hline \multicolumn{3}{|l|}{ Strain } \\
\hline CEN.PK102-3A & MATo leu2-3, 112 ura3-52 & [17] \\
\hline BSW1A1 & CEN.PK102-3A derivative; $\{$ YIp5-ara $\}$ & This work \\
\hline BSW1AY & CEN.PK102-3A derivative; $\{$ YIp5-ara, pYX242\} & This work \\
\hline BSW1A7 & CEN.PK102-3A derivative; $\{$ YIp5-ara, pYX2422-HXT7araA $\}$ & This work \\
\hline BSW1AT & CEN.PK102-3A derivative; $\{$ YIp5-ara, pYX2422-TEF1araA $\}$ & This work \\
\hline BSW2AP & $\begin{array}{l}\text { BSW1AT, gre3 }(-241,+338):: \\
\text { TPI1p-RKI1-RKI1t-PGK1p-TAL1-TAL1t-FBA1p-TKL1-TKL1t-ADH1p-RPE1-RPE1t-loxP }\end{array}$ & This work \\
\hline BSW3AP & BSW2AP, selected for oxygen-limited growth on L-arabinose & This work \\
\hline BSW3AG & BSW3AP derivative; $\{\mathrm{pJFE} 318-G A L 2\}$ & This work \\
\hline \multicolumn{3}{|l|}{ Plasmid } \\
\hline pUG6 & E. coli plasmid with segment LoxP-KanMX4-LoxP & {$[18]$} \\
\hline pJPPP3 & $\begin{array}{l}\text { pUC19-based yeast integration plasmid, containing GRE3-targeting recombinant arms, } \\
\text { overexpression cassette of Sc-TAL1,Sc-TKL1,Sc-RPE1,Sc-RKI1, and selectable marker } \\
\text { loxP-KanMX4-loxP }\end{array}$ & {$[19]$} \\
\hline YEp24-PGKp & $2 \mu U R A 3$ & {$[20]$} \\
\hline $\mathrm{pHX}$ & YEp24-PGKp PGK1p::HXT7p & This work \\
\hline YIp5 & Integration plasmid, Ura3 & {$[21]$} \\
\hline YIp5-ara & $\begin{array}{l}\text { YIp5-HXT7p-araA-PGK1t-HXT7p-araB-PGK1t-HXT7p-araD-PGK1t, and selectable } \\
\text { marker loxP-KanMX4-loxP }\end{array}$ & This work \\
\hline pYX242 & $2 \mu L E U 2$ & {$[22]$} \\
\hline pYX242-WS & pYX242-PGK1t-TEF1p & This work \\
\hline pYX2422-TEF1araA & pYX242-PGK1t-TEF1p-araA & This work \\
\hline pYX2422-HXT7araA & pYX242-PGK1t-HXT7p-araA & This work \\
\hline pJFE3 & $2 \mu U R A 3$ & {$[23]$} \\
\hline pJFE3-GAL2 & pJFE3-TEF1p-GAL2-PGK1t & This work \\
\hline pJFE318-GAL2 & pJFE3-GAL2 URA3::KanMX4 & This work \\
\hline
\end{tabular}

mutants based on its excellent growth on L-arabinose. The plasmid pJFE318-GAL2 was then transformed into strain $\mathrm{BSW} 3 \mathrm{AP}$, resulting in strain BSW3AG.

2.4. Real-Time Quantitative PCR. The cells were cultured in SC medium containing $20 \mathrm{~g} \mathrm{~L}^{-1}$ glucose and collected when the $\mathrm{OD}_{600}$ of cultures reached 1 . The total RNA was extracted using TRIzol reagent (Sangon, China). The first strand of cDNA was reverse transcribed from $1 \mu \mathrm{g}$ of total RNA using PrimeScript RT reagent kits with gDNA Eraser (Takara, Japan). Diluted cDNA products were used for realtime quantitative PCR using the SYBR Green Real-time PCR Master Mix (TOYOBO, Japan) and the LightCycle PCR System (Roche Molecular Biochemicals, Germany). The actin-encoding gene $A C T 1$ was used as the reference gene for normalization. The data of real-time PCR was calculated according to the $2^{-\Delta \Delta C T}$ method $[19,27]$. The primers for these PCR were listed in Table 2.

2.5. Fermentation. A single colony was cultured overnight in SC medium containing $20 \mathrm{~g} \mathrm{~L}^{-1}$ glucose. A sample of the overnight culture was diluted to an initial $\mathrm{OD}_{600}$ of 0.5 in SC medium containing $10 \mathrm{~g} \mathrm{~L}^{-1}$ glucose and $10 \mathrm{~g} \mathrm{~L}^{-1} \mathrm{~L}$ arabinose. After $10 \mathrm{~h}$ cultivation, the cells were collected and used for fermentation. All the shaker flask fermentations were performed at $30^{\circ} \mathrm{C}, 200 \mathrm{r} \mathrm{min}^{-1}$, in $200 \mathrm{~mL}$ shaker flasks containing $40 \mathrm{~mL}$ medium. The oxygen-limited condition was maintained by using a rubber stopper. The batch fermentations under anaerobic conditions were performed in $1.4 \mathrm{~L}$ fermentors (Infors AG, Switzerland) with a working volume of $900 \mathrm{~mL}$. Anaerobic conditions were maintained by sparging with nitrogen $\left(0.1 \mathrm{~L} \mathrm{~min}^{-1}\right)$; the agitation rate was $500 \mathrm{rmin}^{-1}$. The $\mathrm{pH}$ was maintained at 5.0 by automatically pumping $1 \mathrm{~mol} \mathrm{~L}^{-1} \mathrm{NaOH}$ and $1 \mathrm{~mol} \mathrm{~L}^{-1} \mathrm{H}_{3} \mathrm{PO}_{4}$ [19]. The initial biomass was $0.2 \mathrm{~g} \mathrm{DCW} \mathrm{L}^{-1}$. The carbon source in the SC plus CSM-LEU-URA medium was $20 \mathrm{~g} \mathrm{~L}^{-1} \mathrm{~L}$-arabinose; $200 \mu \mathrm{g} \mathrm{mL}^{-1} \mathrm{G} 418$ was supplied in the fermentation of strain BSW3AG. The dry cell weight of evolved strains and the unevolved strains were calculated according to the formula of dry weight $\left(\mathrm{mg} \mathrm{mL}^{-1}\right)=0.266 \times \mathrm{OD}_{600}-0.0762$ and dry weight $\left(\mathrm{mg} \mathrm{mL}^{-1}\right)=0.2365 \times \mathrm{OD}_{600}+0.1149$, respectively.

2.6. Analysis of Fermentation Products. The high performance liquid chromatography (HPLC) Prominence LC20A (Shimadzu, Japan) equipped with the refractive index 


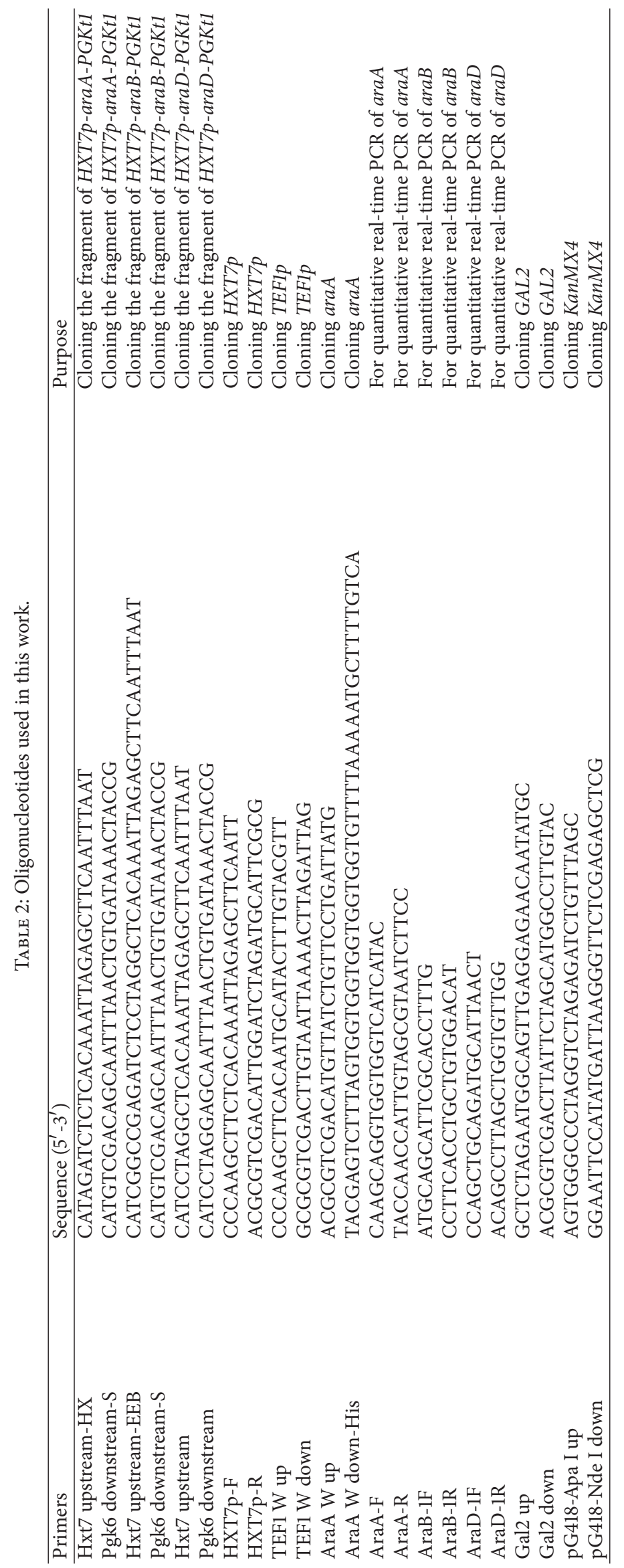




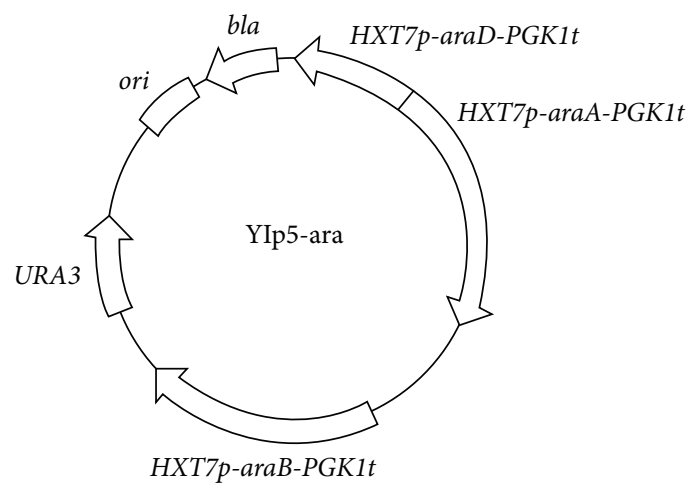

(a)

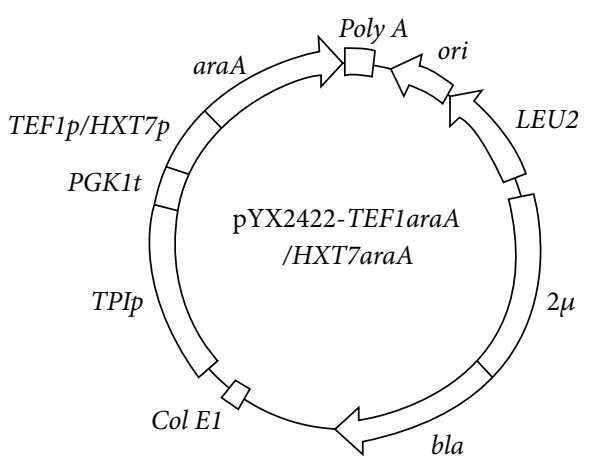

(b)

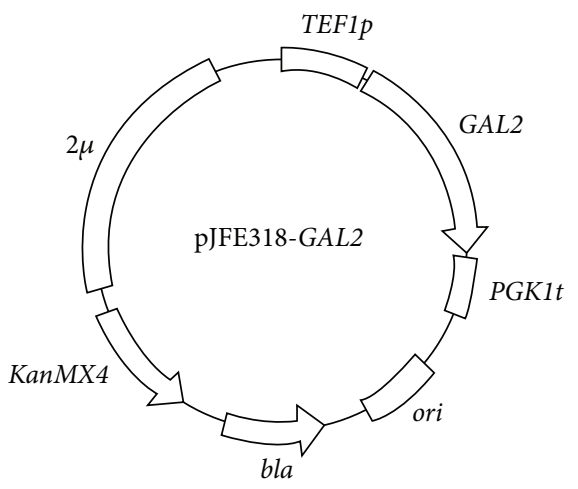

(c)

FIGURE 1: The physical maps of the plasmids (a) YIp5-ara, (b) pYX2422-TEF1araA/HXT7araA, and (c) pJFE318-GAL2.

detector RID-10A (Shimadzu, Japan) was used to determine the concentrations of sugars and metabolites. The Aminex HPX-87P ion exchange column (Bio-Rad, USA) was used to analyze L-arabinose, arabitol, and ethanol at $80^{\circ} \mathrm{C}$ with a mobile phase of water at a flow rate of $0.6 \mathrm{~mL} \mathrm{~min}^{-1}$. The Aminex HPX-87H ion exchange column (Bio-Rad, Hercules, USA) was used to analyze glycerol and acetate at $45^{\circ} \mathrm{C}$ using $5 \mathrm{mmol} \mathrm{L}^{-1} \mathrm{H}_{2} \mathrm{SO}_{4}$ as the mobile phase [12].

\section{Results}

3.1. Expression of the Codon-Optimized Genes Involved in the L-Arabinose Pathway in S. cerevisiae. Based on the amino acid sequence of L-arabinose isomerase (GenBank accession no. CCC80517.1), L-ribulokinase (GenBank accession no. CCC80519.1), and L-ribulose-5-phosphate 4epimerase (GenBank accession no. CCC80518.1) recorded in the National Center for Biotechnology Information (NCBI, http://www.ncbi.nlm.nih.gov/), the $\operatorname{araA}$, $\operatorname{araB}$, and $\operatorname{araD}$ genes of $L$. plantarum were artificially synthesized using $S$. cerevisiae preferred codons. The CAIs of codon-optimized $\operatorname{ara} A, \operatorname{ara} B$, and $a r a D$ were $0.599,0.580$, and 0.646 , respectively, which were higher than those of the native sequences (0.324, 0.223 , and 0.243 , resp.).

The expression cassettes of codon-optimized araA, $a r a B$, and $a r a D$ were integrated into the chromosome of strain CEN.PK102-3A, resulting in strain BSW1A1. However,
BSW1A1 could not grow on L-arabinose, although the transcribed mRNAs of these genes were all detectable. Then, more copies of araA were introduced into BSW1A1, carried by the episomal plasmid pYX242 and expressed under control of the HXT7 and TEF1 promoters. The transcriptional levels of araA in the resulting strains, BSW1A7 and BSW1AT, were $12.9 \pm$ 2.9-fold and 32.5 \pm 0.7 -fold higher than in the reference strain BSW1AY carrying only the integrated, expressed $\operatorname{araA}$. The BSW1A7 and BSW1AT strains were aerobically incubated on L-arabinose, and the growth of strain BSW1AT was observed after $\sim 150 \mathrm{~h}$, whereas BSW1A7 could not grow even when cultured longer.

3.2. Improvement of the L-Arabinose Utilization in S. cerevisiae by Engineering and Evolution. The TAL1, TKL1, RPE1, and $R K I 1$ genes involved in the nonoxidative pentose phosphate pathway were overexpressed in a single colony isolated from the BSW1AT $150 \mathrm{~h}$ culture by integrating the linearized plasmid pJPPP3 [19] into the chromosome. The resulting strain, BSW2AP, was evolved on L-arabinose. After 9 transfers in aerobic conditions and 12 transfers in oxygen-limited conditions, the doubling time of the culture decreased from $22 \mathrm{~h}$ to $4.5 \mathrm{~h}$. The mutants were screened on L-arabinose plates, and a large colony was selected and named BSW3AP.

The transcriptional levels of genes in the recombinant strains BSW1AT, BSW2AP, and BSW3AP were determined by real-time quantitative PCR (Figure 2). The araA expression 


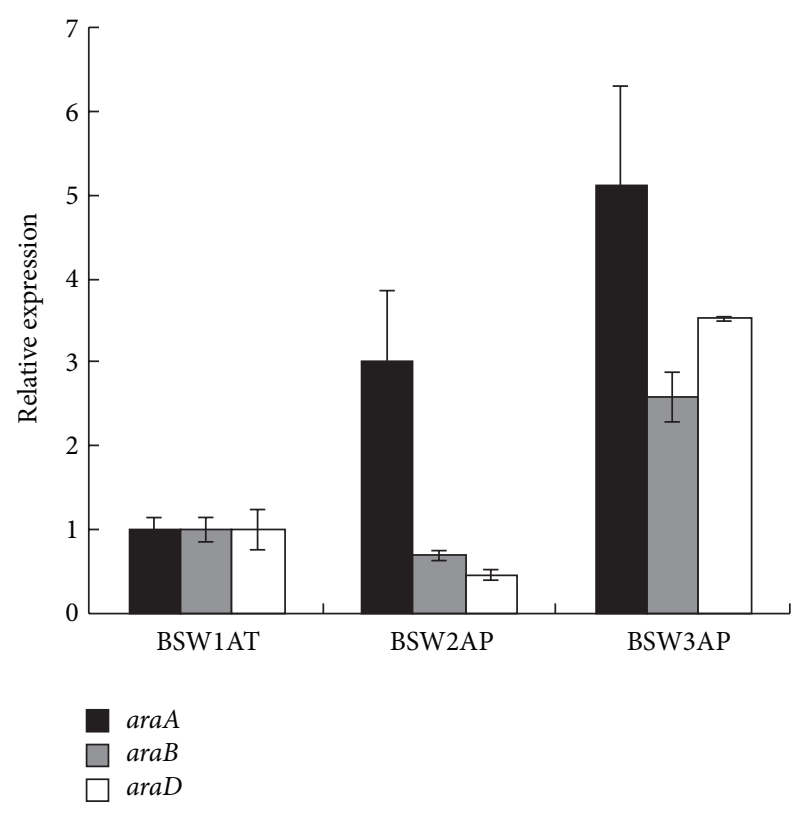

FIgURE 2: The expression of $\operatorname{araA}$ (black bars), $\operatorname{araB}$ (gray bars), and araD (blank bars) of strains BSW2AP and BSW3AP compared to strain BSW1AT. The fold-changes of mRNA levels of these genes are normalized to the expression of ACT1. The tested strains were cultivated on $20 \mathrm{~g} \mathrm{~L}^{-1}$ glucose. The values given are obtained from three independent measurements.

level in BSW2AP was 2-fold higher than in BSW1AT, whereas the expression levels of $a r a B$ and $a r a D$ in BSW2AP were lower. These changes might be due to mutations that occurred during the cultivation of BSW1AT on L-arabinose. In the evolved strain BSW3AP, all three genes were expressed at high levels. The $\operatorname{araA}, \operatorname{araB}$, and $a r a D$ expression levels in BSW3AP were 4.1-fold, 1.6-fold, and 2.5-fold higher than those in strain BSW1AT, respectively.

The L-arabinose utilization of strains BSW1AT, BSW2AP, and BSW3AP was compared in shaker-flasks under oxygenlimited conditions (Figure 3); the initial $\mathrm{OD}_{600}$ was 0.5 . No growth of BSW1AT was observed within $120 \mathrm{~h}$. The strain BSW2AP grew on L-arabinose with a maximum specific growth rate $\left(\mu_{\max }\right)$ of $0.011 \mathrm{~h}^{-1} ; 4.4 \mathrm{~g} \mathrm{~L}^{-1} \mathrm{~L}$-arabinose was consumed, and $1.2 \mathrm{~g} \mathrm{~L}^{-1}$ ethanol was produced in $120 \mathrm{~h}$ of fermentation. In contrast, the $\mu_{\max }$ of the evolved strain BSW3AP increased to $0.23 \mathrm{~h}^{-1}$. After $120 \mathrm{~h}$ of fermentation, $18.6 \mathrm{~g} \mathrm{~L}^{-1} \mathrm{~L}$-arabinose had been consumed with a maximum specific consumption rate of $0.7 \mathrm{~g} \mathrm{~h}^{-1} \mathrm{~g}^{-1} \mathrm{DCW} ; 6.9 \mathrm{~g} \mathrm{~L}^{-1}$ ethanol had been produced, and the ethanol yield was $0.43 \mathrm{~g} \mathrm{~g}^{-1}$; only $0.13 \mathrm{~g} \mathrm{~L}^{-1} \mathrm{~L}$-arabitol had accumulated.

3.3. Overexpression of GAL2 Improved the L-Arabinose Anaerobic Fermentation of the Evolved Strain. The galactose permease gene GAL2 was overexpressed in BSW3AP, resulting in strain BSW3AG. The anaerobic L-arabinose fermentation properties of strain BSW3AP and BSW3AG were studied (Figure 4 and Table 3 ) in bioreactors. Strain BSW3AP grew on L-arabinose with a maximum specific growth rate of
$0.067 \mathrm{~h}^{-1}$. The maximum specific consumption rate of $\mathrm{L}$ arabinose was $0.49 \mathrm{~g} \mathrm{~h}^{-1} \mathrm{~g}^{-1} \mathrm{DCW}$. Ethanol was produced at a maximum specific rate of $0.20 \mathrm{~g} \mathrm{~h}^{-1} \mathrm{~g}^{-1} \mathrm{DCW}$ with a yield of $0.42 \mathrm{~g} \mathrm{~g}^{-1}$. The overexpression of GAL2 significantly improved the L-arabinose fermentation capacity. The maximum specific growth rate of BSW3AG was $0.075 \mathrm{~h}^{-1}$, which was $12 \%$ faster than that of BSW3AP. The L-arabinose specific consumption rate of BSW3AG was $0.61 \mathrm{~g} \mathrm{~h}^{-1} \mathrm{~g}^{-1} \mathrm{DCW}$, which was $24 \%$ faster than that of BSW3AP. The ethanol production rate was $0.27 \mathrm{~g} \mathrm{~h}^{-1} \mathrm{~g}^{-1} \mathrm{DCW}$, and the ethanol yield was $0.43 \mathrm{~g} \mathrm{~g}^{-1}$. Furthermore, both BSW3AP and BSW3AG produced small amounts of glycerol $\left(1.4 \mathrm{~g} \mathrm{~L}^{-1}\right.$ for both strains) and almost undetectable amounts of arabitol and acetate.

\section{Discussion}

The complete conversion of sugars is important for efficient and cost-effective fuel ethanol production from lignocellulosic materials. Even small improvements in substrate utilization can significantly decrease the costs of the whole process [28]. L-arabinose is an important component of lignocellulosic materials. Expression of the L. plantarum Larabinose pathway has proven to be effective in constructing L-arabinose utilizing S. cerevisiae [8]. Given that the codonoptimized genes might lead to increased expression of the proteins $[15,29]$, in the present work, the original araA, $a r a B$, and $a r a D$ genes of $L$. plantarum were modified to match the codon usage of $S$. cerevisiae and then integrated into the chromosome of strain CEN.PK102-3A. However, this recombinant strain could not grow on L-arabinose. More copies of the araA gene were then introduced into the recombinant strain under the control of the HXT7 and TEF1 promoters. When the two resulting strains were cultured on L-arabinose, growth was only observed in cultures of the strain expressing araA under the control of the TEF1 promoter, in which the araA transcriptional level was 1.4-fold higher than in the strain expressing araA controlled by the HXT7 promoter. We suggest that only when the transcription level of $\operatorname{araA}$ is higher than a certain level can growth on L-arabinose occur. In contrast, only one copy of $\operatorname{araB}$ and $a r a D$ was introduced into this recombinant strain, and the transcriptional levels of these genes were lower than in the parental strain. These phenomena indicated that $\operatorname{araB}$ and araD were less important for growth on L-arabinose because only one copy of these genes allowed the recombinant strain to grow on L-arabinose.

Adaptive evolution was proven to be a powerful method to enhance the strains' metabolic efficiency $[8,13]$. In the present study, the evolved strain BSW3AP shows significantly improved L-arabinose metabolizing capacity. The increased transcription levels of all the three genes ( $\operatorname{rraA}, \operatorname{araB}$, and $\operatorname{araD})$ might contribute to the enhancement. Compared to $\operatorname{ara} A$ and $a r a D$, the expression level of $a r a B$ was lower. Becker and Boles [13] reported that a mutant on L-arabinose decreased the L-ribulokinase activity expressed by $a r a B$. The relatively lower expression of $a r a B$ avoids the overconsumption of ATP, which would benefit the growth of the strain on L-arabinose. 


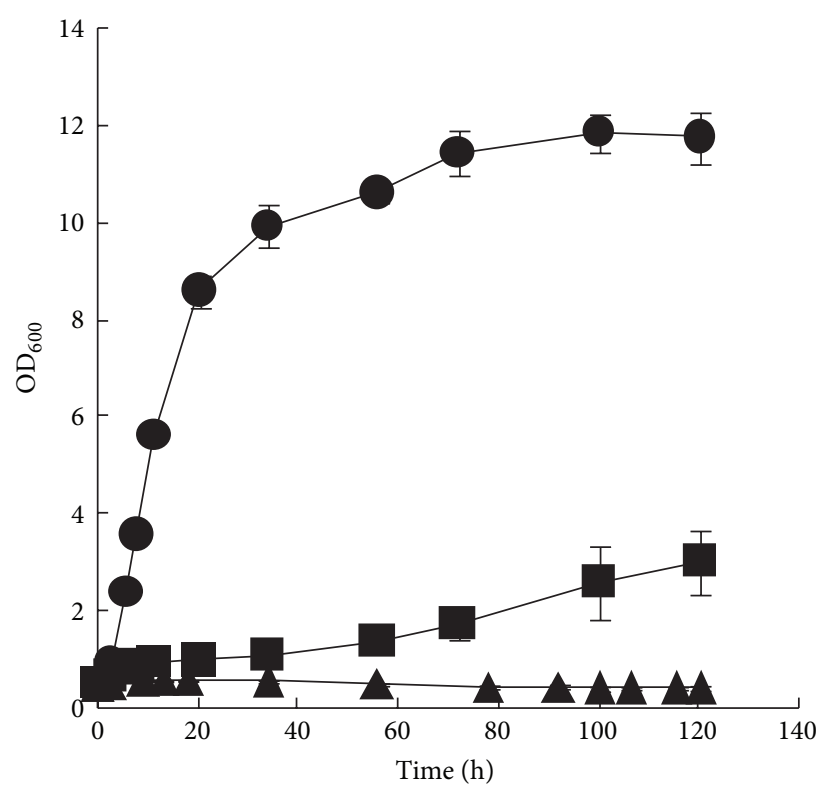

(a)

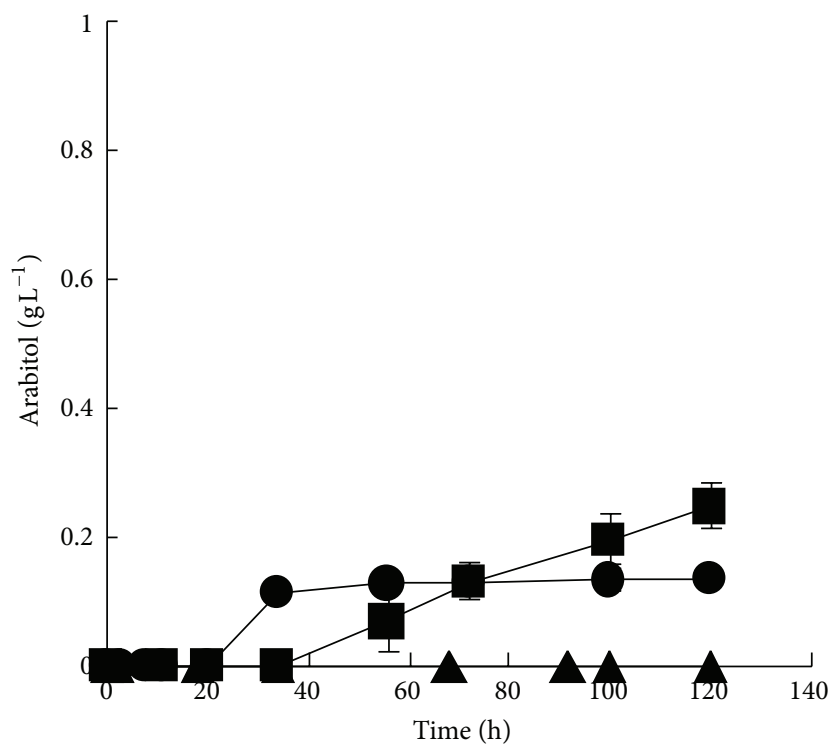

(c)

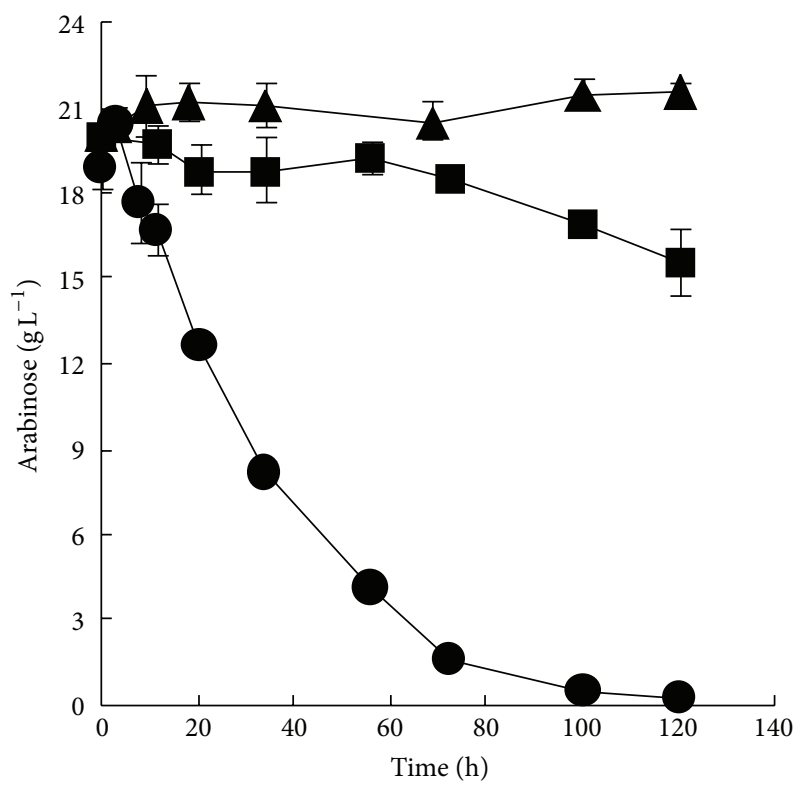

(b)

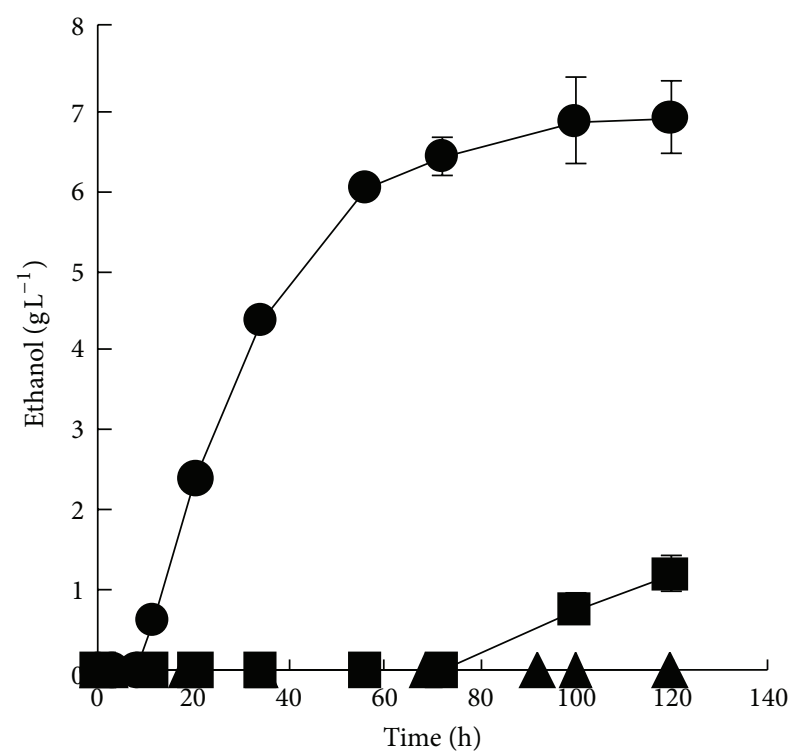

(d)

Figure 3: The L-arabinose fermentation of strains in shaker flasks. Growth capacity (a), L-arabinose consumption (b), arabitol formation (c),

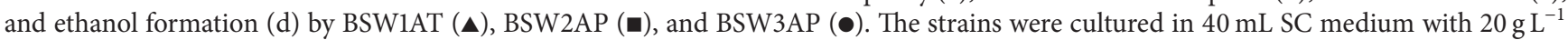
$\mathrm{L}$-arabinose at $30^{\circ} \mathrm{C}, 200 \mathrm{r} \mathrm{min}^{-1}$ with an initial $\mathrm{OD}_{600}$ of 0.5 . The data are the averages of three independent experiments.

TABLE 3: The maximum specific growth rates $\left(\mu_{\max }\right)$, the maximum specific L-arabinose-consumption rate, the ethanol production rate, and the ethanol yield for BSW3AP and BSW3AG on $20 \mathrm{~g} \mathrm{~L}^{-1} \mathrm{~L}$-arabinose.

\begin{tabular}{lcccc}
\hline Strain & $\mu_{\max }\left(\mathrm{h}^{-1}\right)$ & $\begin{array}{c}\text { The maximum specific } \\
\mathrm{L} \text {-arabinose consumption rate } \\
\left(\mathrm{g} \mathrm{h}^{-1} \mathrm{~g}^{-1} \mathrm{DCW}\right)\end{array}$ & $\begin{array}{c}\text { Ethanol production rate } \\
\left(\mathrm{g} \mathrm{h}^{-1} \mathrm{~g}^{-1} \mathrm{DCW}\right)\end{array}$ & $\begin{array}{c}\text { Ethanol yield } \\
\left(\mathrm{g} \mathrm{g}^{-1} \mathrm{~L}-\mathrm{arabinose} \mathrm{consumed}\right)\end{array}$ \\
\hline BSW3AP & 0.067 & 0.49 & 0.20 & 0.42 \\
BSW3AG & 0.075 & 0.61 & 0.27 & 0.43 \\
\hline
\end{tabular}




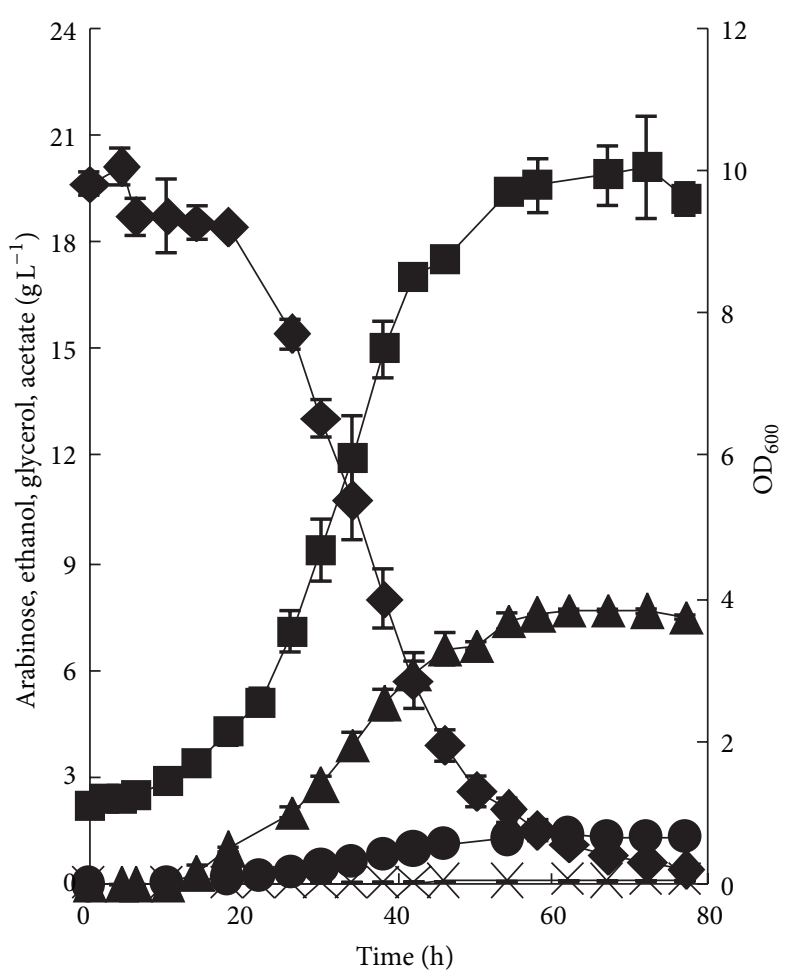

(a)

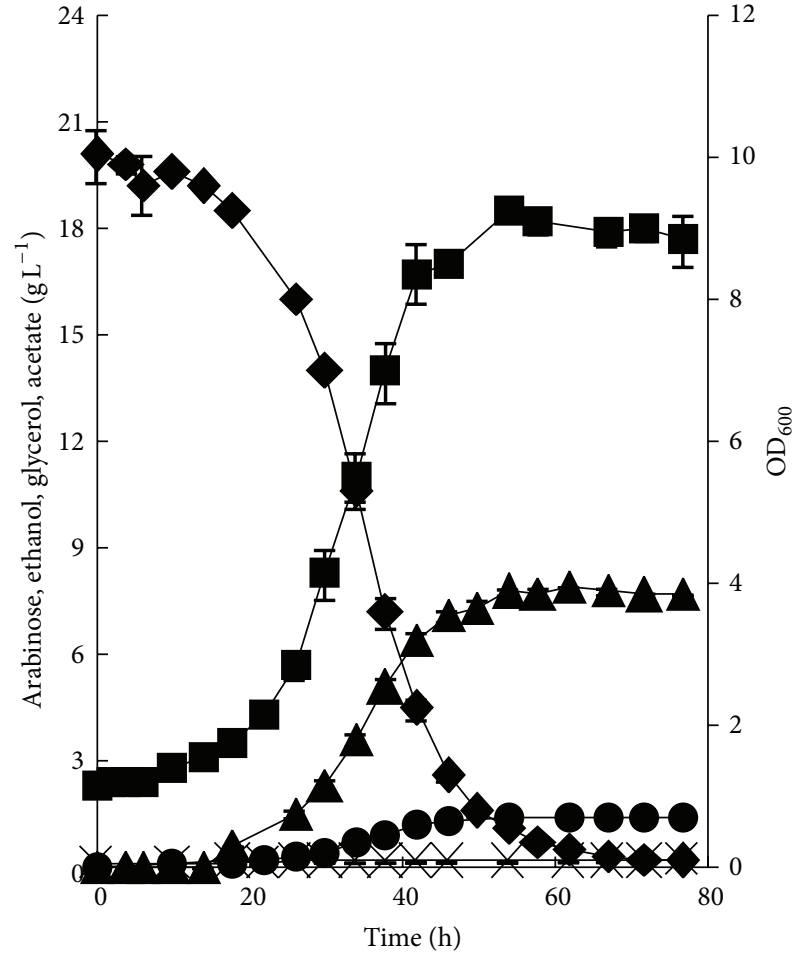

(b)

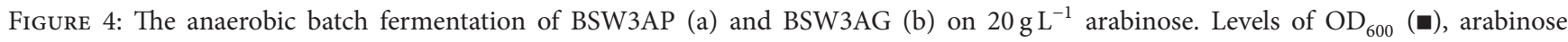
$(\bullet)$, ethanol $(\boldsymbol{\Delta})$, Glycerol $(\bullet)$, and acetate $(\times)$. The fermentation was performed in $1.4 \mathrm{~L}$ fermentors with a working volume of $900 \mathrm{~mL}$. Anaerobic conditions were maintained by sparging nitrogen $\left(0.1 \mathrm{~L} \mathrm{~min}^{-1}\right)$; the agitation rate was $500 \mathrm{rmin}^{-1}$. The $\mathrm{pH}$ was maintained at 5.0 by automatically pumping in $1 \mathrm{~mol} \mathrm{~L}^{-1} \mathrm{NaOH}$ and $1 \mathrm{~mol} \mathrm{~L}^{-1} \mathrm{H}_{3} \mathrm{PO}_{4}$. The initial biomass was $0.2 \mathrm{~g} \mathrm{DCW} \mathrm{L}$. The $20 \mathrm{~g} \mathrm{~L}^{-1} \mathrm{~L}$-arabinose was used as the carbon source in SC plus CSM-LEU-URA medium, and $200 \mu \mathrm{g} \mathrm{mL}^{-1}$ G418 was supplied in the fermentation of strain BSW3AG. The data are the average of duplicate determinations.

L-arabinose is a novel carbon source for S. cerevisiae. The uptake of L-arabinose in S. cerevisiae mainly depends on the nonspecific transport by the hexose transporter Gal2p. The Hxt9p and Hxt10p also can transport L-arabinose, but the efficiency is very low [30]. It was reported that overexpressing GAL2 improves the L-arabinose utilization $[13,16]$. In this study, overexpressing GAL2 notably increased the growth rate and L-arabinose consumption rate of our evolved strain BSW3AP. This result suggested that the theoretical L-arabinose metabolic flux was higher than we detected in BSW3AP. The L-arabinose utilization of BSW3AP was limited by its absorption rate. When the GAL2 was overexpressed, more Gal2p in the plasma membrane lead to an increased $\mathrm{L}$-arabinose uptake and then promote the L-arabinose utilization. Our result further confirmed the importance of transporters for L-arabinose utilization; however, the affinity of Gal2p for L-arabinose is low, and glucose competitively inhibited its binding to L-arabinose [30]. Improving the efficiency of the L-arabinose specific transporter remains to be conducted.

\section{Conclusions}

With multiple steps of genetic engineering and adaptive evolution, we obtained the strain BSW3AG, which grows on
$\mathrm{L}$-arabinose with a $\mu_{\max }$ of $0.075 \mathrm{~h}^{-1}$. The maximum specific $\mathrm{L}$-arabinose consumption rate is $0.27 \mathrm{~g} \mathrm{~h}^{-1} \mathrm{~g}^{-1} \mathrm{DCW}$, and the maximum ethanol yield is $0.43 \mathrm{~g} \mathrm{~g}^{-1} \mathrm{~L}$-arabinose consumed, which is $84.3 \%$ of the theoretical amount. A high level of ara $\mathrm{A}$ expression is notably important in establishing an efficient Larabinose pathway in S. cerevisiae, and more efficient transporters are necessary to improve the L-arabinose absorption capacity of the evolved strains.

\section{Conflict of Interests}

The authors declare that they have no conflict of interests.

\section{Acknowledgments}

This work was supported by the National Key Basic Research Program (2011CB707405), the National High-Technology Research and Development Program of China under Grant (2012AA022106), the National Natural Science Foundation of China (30970091, 31070096, and 31270151), and the International S\&T Cooperation Program of China (2010DFA32560). The authors thank Dr. Peter Kötter from Johann Wolfgang Goethe-University Frankfurt for the strain CEN.PK102-3A. 


\section{References}

[1] R. den Haan, H. Kroukamp, M. Mert, M. Bloom, J. F. Görgens, and W. H. van Zyl, "Engineering Saccharomyces cerevisiae for next generation ethanol production," Journal of Chemical Technology \& Biotechnology, vol. 88, no. 6, pp. 983-991, 2013.

[2] W. E. Mabee, "Policy options to support biofuel production," Advances in Biochemical Engineering/Biotechnology, vol. 108, pp. 329-357, 2007.

[3] A. E. Farrell, R. J. Plevin, B. T. Turner, A. D. Jones, M. O’Hare, and D. M. Kammen, "Ethanol can contribute to energy and environmental goals," Science, vol. 311, no. 5760, pp. 506-508, 2006.

[4] B. Hahn-Hägerdal, M. Galbe, M. F. Gorwa-Grauslund, G. Lidén, and G. Zacchi, "Bio-ethanol-the fuel of tomorrow from the residues of today," Trends in Biotechnology, vol. 24, no. 12, pp. 549-556, 2006.

[5] M. Galbe and G. Zacchi, "A review of the production of ethanol from softwood," Applied Microbiology and Biotechnology, vol. 59, no. 6, pp. 618-628, 2002.

[6] S. R. Kim, S. Ha, N. Wei, E. J. Oh, and Y. Jin, "Simultaneous co-fermentation of mixed sugars: a promising strategy for producing cellulosic ethanol," Trends in Biotechnology, vol. 30, no. 5, pp. 274-282, 2012.

[7] B. Seiboth and B. Metz, "Fungal arabinan and L-arabinose metabolism," Applied Microbiology and Biotechnology, vol. 89, no. 6, pp. 1665-1673, 2011.

[8] H. W. Wisselink, M. J. Toirkens, M. D. R. F. Berriel et al., "Engineering of Saccharomyces cerevisiae for efficient anaerobic alcoholic fermentation of L-arabinose," Applied and Environmental Microbiology, vol. 73, no. 15, pp. 4881-4891, 2007.

[9] B. Hahn-Hägerdal, K. Karhumaa, M. Jeppsson, and M. F. Gorwa-Grauslund, "Metabolic engineering for pentose utilization in Saccharomyces cerevisiae," Advances in Biochemical Engineering/Biotechnology, vol. 108, pp. 147-177, 2007.

[10] R. Schleif, "Regulation of the L-arabinose operon of Escherichia coli," Trends in Genetics, vol. 16, no. 12, pp. 559-565, 2000.

[11] C. Fonseca, R. Romão, H. R. de Sousa, B. Hahn-Hägerdal, and I. Spencer-Martins, "L-arabinose transport and catabolism in yeast,” FEBS Journal, vol. 274, no. 14, pp. 3589-3600, 2007.

[12] M. Bettiga, O. Bengtsson, B. Hahn-Hägerdal, and M. F. GorwaGrauslund, "Arabinose and xylose fermentation by recombinant Saccharomyces cerevisiae expressing a fungal pentose utilization pathway," Microbial Cell Factories, vol. 8, article 40, 2009.

[13] J. Becker and E. Boles, "A modified Saccharomyces cerevisiae strain that consumes L-arabinose and produces ethanol," Applied and Environmental Microbiology, vol. 69, no. 7, pp. 41444150, 2003.

[14] M. Sedlak and N. W. Y. Ho, "Expression of E. coliaraBAD operon encoding enzymes for metabolizing L-arabinose in Saccharomyces cerevisiae," Enzyme and Microbial Technology, vol. 28, no. 1, pp. 16-24, 2001.

[15] B. Wiedemann and E. Boles, "Codon-optimized bacterial genes improve L-arabinose fermentation in recombinant Saccharomyces cerevisiae," Applied and Environmental Microbiology, vol. 74, no. 7, pp. 2043-2050, 2008.

[16] H. W. Wisselink, C. Cipollina, B. Oud et al., "Metabolome, transcriptome and metabolic flux analysis of arabinose fermentation by engineered Saccharomyces cerevisiae," Metabolic Engineering, vol. 12, no. 6, pp. 537-551, 2010.

[17] K. D. Entian and P. Kötter, " 23 yeast mutant and plasmid collections," in Methods in Microbiology, J. P. B. Alistair and
T. Mick, Eds., pp. 431-449, Academic Press, New York, NY, USA, 1998.

[18] U. Güldener, S. Heck, T. Fiedler, J. Beinhauer, and J. H. Hegemann, "A new efficient gene disruption cassette for repeated use in budding yeast," Nucleic Acids Research, vol. 24, no. 13, pp. 2519-2524, 1996.

[19] B. Peng, Y. Shen, X. Li, X. Chen, J. Hou, and X. Bao, "Improvement of xylose fermentation in respiratory-deficient xylosefermenting Saccharomyces cerevisiae," Metabolic Engineering, vol. 14, no. 1, pp. 9-18, 2012.

[20] M. Walfridsson, M. Anderlund, X. Bao, and B. Hahn-Hägerdal, "Expression of different levels of enzymes from the Pichia stipitis XYL1 and XYL2 genes in Saccharomyces cerevisiae and its effects on product formation during xylose utilisation," Applied Microbiology and Biotechnology, vol. 48, no. 2, pp. 218-224, 1997.

[21] K. Struhl, D. T. Stinchcomb, S. Scherer, and R. W. Davis, "Highfrequency transformation of yeast: autonomous replication of hybrid DNA molecules," Proceedings of the National Academy of Sciences of the United States of America, vol. 76, no. 3, pp. 1035$1039,1979$.

[22] X. Liu, X. Zhang, C. Wang, L. Liu, M. Lei, and X. Bao, "Genetic and comparative transcriptome analysis of bromodomain factor 1 in the salt stress response of Saccharomyces cerevisiae," Current Microbiology, vol. 54, no. 4, pp. 325-330, 2007.

[23] Y. Shen, X. Chen, B. Peng, L. Chen, J. Hou, and X. Bao, "An efficient xylose-fermenting recombinant Saccharomyces cerevisiae strain obtained through adaptive evolution and its global transcription profile," Applied Microbiology and Biotechnology, vol. 96, no. 4, pp. 1079-1091, 2012.

[24] P. M. Sharp and W. Li, "The codon adaptation index-a measure of directional synonymous codon usage bias, and its potential applications," Nucleic Acids Research, vol. 15, no. 3, pp. 1281-1295, 1987.

[25] L. Ji, Y. Shen, L. Xu, B. Peng, Y. Xiao, and X. Bao, "Enhanced resistance of Saccharomyces cerevisiae to vanillin by expression of lacA from Trametes sp. AH28-2," Bioresource Technology, vol. 102, no. 17, pp. 8105-8109, 2011.

[26] R. D. Gietz, R. H. Schiestl, A. R. Willems, and R. A. Woods, "Studies on the transformation of intact yeast cells by the LiAc/SS-DNA/PEG procedure," Yeast, vol. 11, no. 4, pp. 355-360, 1995.

[27] K. J. Livak and T. D. Schmittgen, "Analysis of relative gene expression data using real-time quantitative PCR and the $2^{-\triangle \Delta \mathrm{CT}}$ method," Methods, vol. 25, no. 4, pp. 402-408, 2001.

[28] M. von Sivers and G. Zacchi, "Ethanol from lignocellulosics: a review of the economy," Bioresource Technology, vol. 56, no. 2-3, pp. 131-140, 1996.

[29] G. Wu, Y. Zheng, I. Qureshi et al., "SGDB: a database of synthetic genes re-designed for optimizing protein over-expression," Nucleic Acids Research, vol. 35, supplement 1, pp. D76D79, 2007.

[30] T. Subtil and E. Boles, "Improving L-arabinose utilization of pentose fermenting Saccharomyces cerevisiae cells by heterologous expression of L-arabinose transporting sugar transporters," Biotechnology for Biofuels, vol. 4, p. 38, 2011. 

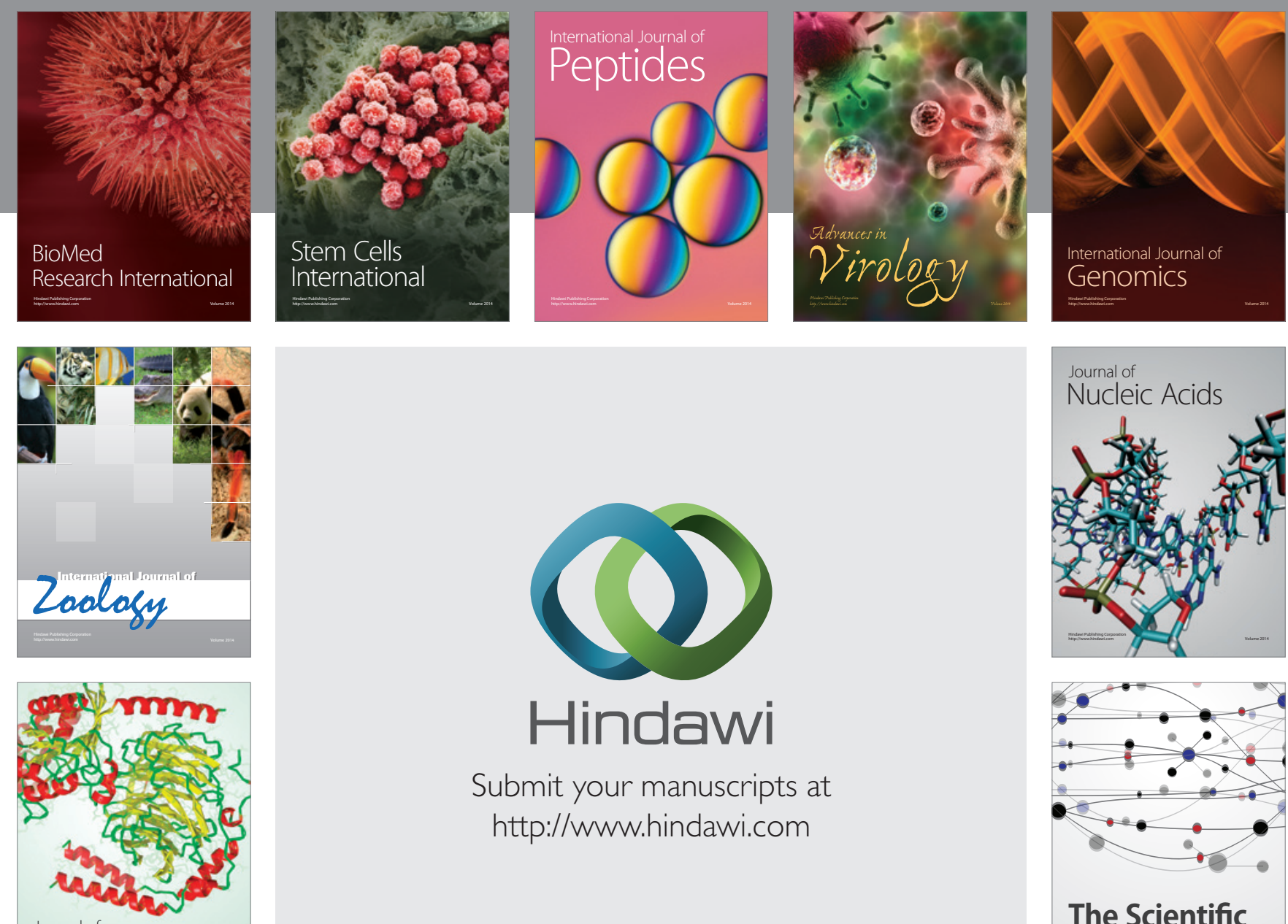

Submit your manuscripts at

http://www.hindawi.com

Journal of
Signal Transduction
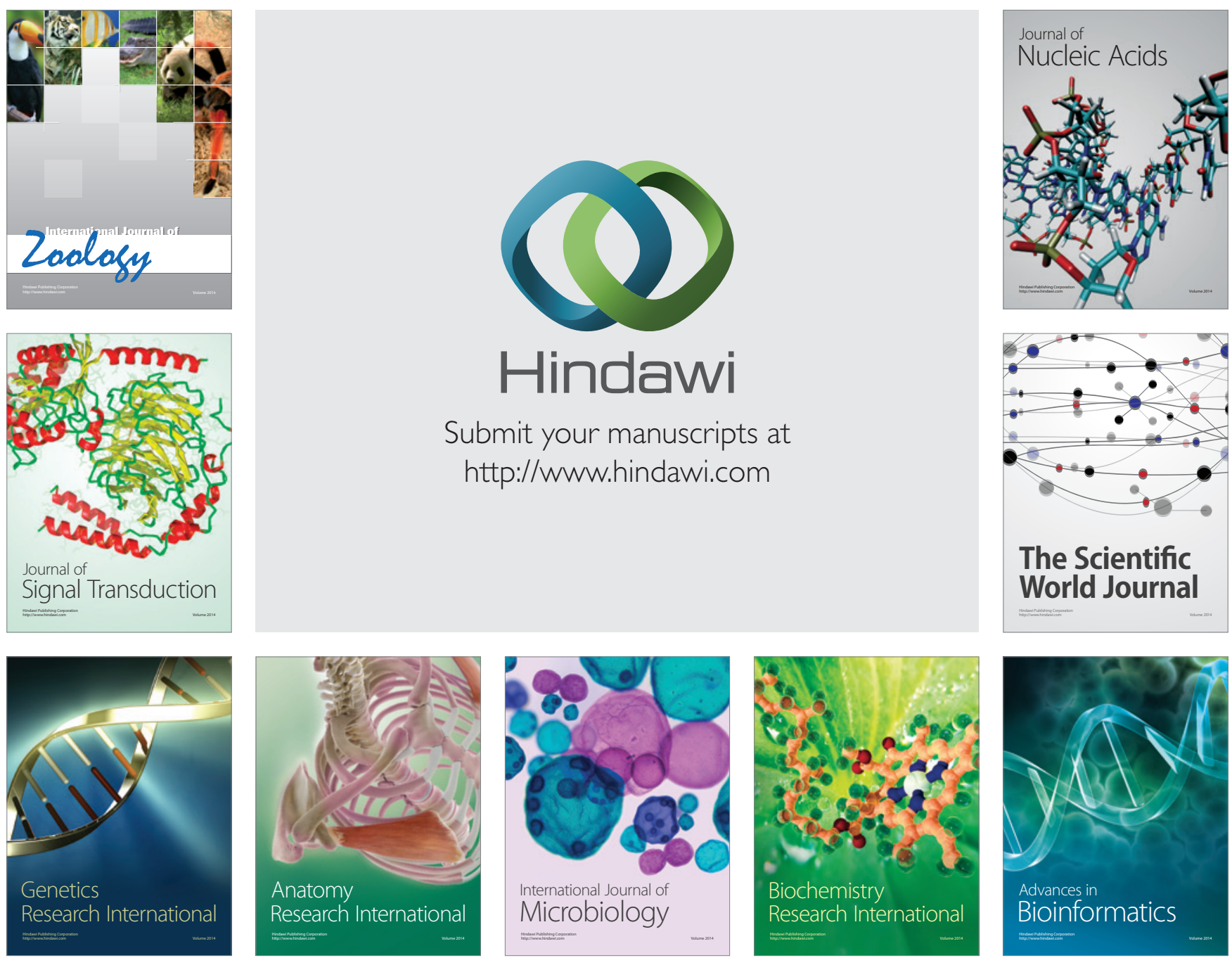

The Scientific World Journal
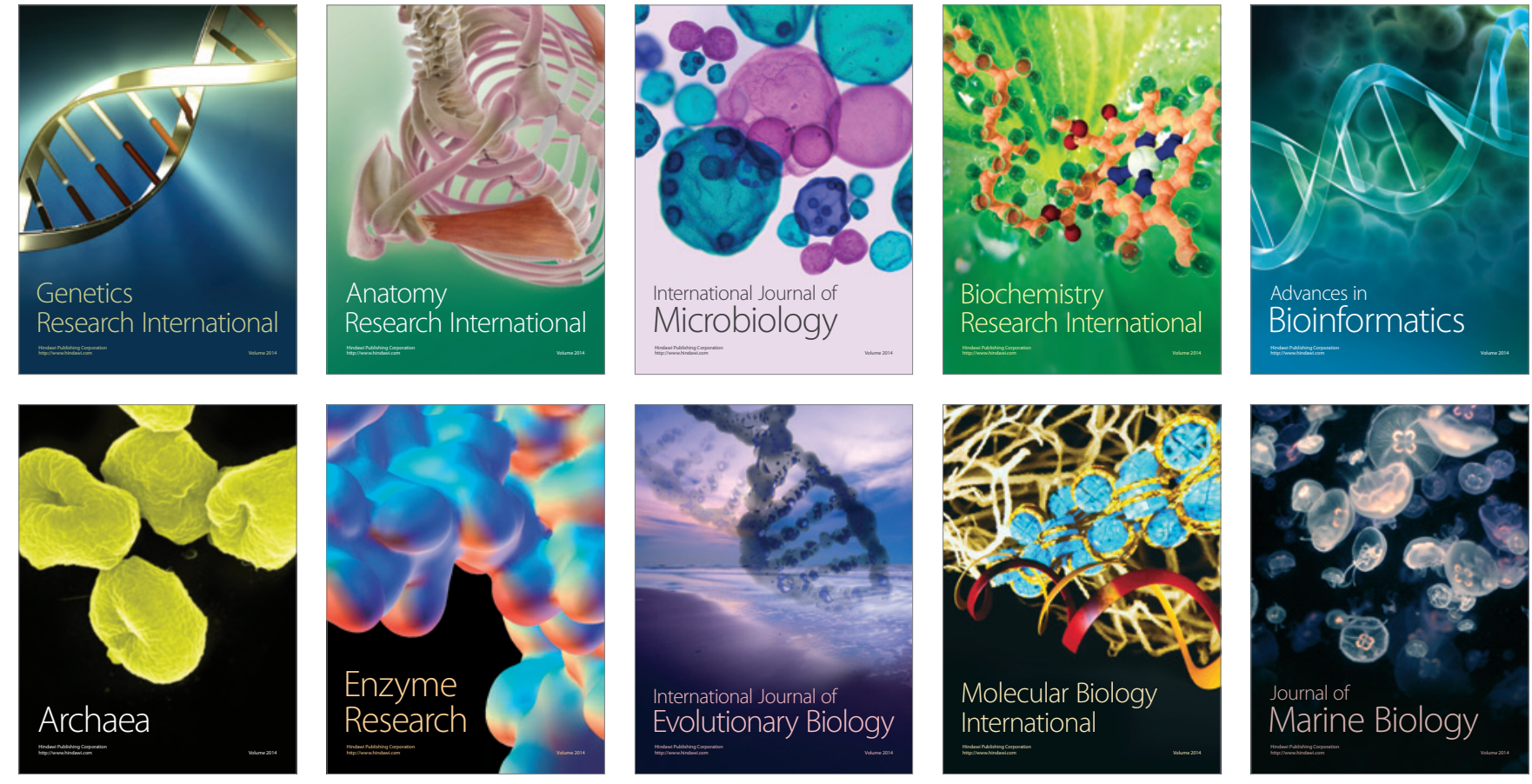